\title{
infraestrutura e desenvolvimento: estudo de caso sobre os estados unidos no século $\mathrm{XIX}^{\star}$
}

\section{infrastructure and development: the case of united states in the $19^{\text {th }}$ century}

\author{
Fernando Dall'Onder Sebben $\star \star$ \\ Senado Federal, Brasília, Distrito Federal, Brasil \\ Pedro Perfeito da Silva ${ }^{\star \star \star}$ \\ Faculdade de Ciências Econômicas, Universidade Federal do Rio Grande do Sul, Porto Alegre, \\ Rio Grande do Sul, Brasil
}

\section{RESUMO}

O presente artigo tem como objetivo geral discutir o papel do Estado na construção da infraestrutura e do setor industrial por meio de um estudo de caso determinado geográfica e temporalmente, os Estados Unidos ao longo do século XIX. Parte-se do argumento de que o sentido do avanço na infraestrutura doméstica é contingente às medidas estatais quanto ao desenvolvimento industrial. Para aprofundar tal argumento e realizar o objetivo geral, inicialmente, detalha-se o conjunto de mudanças infraestruturais ocorridas ao longo do século XIX, atentando para a relação entre elas e o desenvolvimento econômico.Após isso, são apresentadas as principais medidas estatais estadunidenses, que confluíram para que o avanço na infraestrutura forjasse uma trajetória de desenvolvimento industrial.

Palavras-chave: Estados Unidos. História econômica. Desenvolvimento industrial. Infraestrutura. Autonomia enraizada.

\section{Abstract}

The present paper has as general objective to discuss the role of the State in the building of infrastructure and the industrial sector through a case study geographically and temporarily delimitated, the United States during the nineteenth century. It is based on the argument that the direction of the domestic infrastructure improvement is contingent on the State measures regarding the industrial development. In order to deepen this argument and to achieve the general objective, we first detail the set of infrastructural changes that took place during the nineteenth century, considering their relation to economic development. After this, we present the main measures of American State, which came together so that the advance in the infrastructure fostered a trajectory of industrial development.

Keywords: United States. Economic history. Industrial development. Infrastructure. Embedded autonomy.

* Submetido: 14 de novembro de 2017; aceito: 2 de janeiro de 2018.

$\star \star$ Analista legislativo do Senado Federal. Doutor em Estudos Estratégicos Internacionais pela Universidade Federal do Rio Grande do Sul.E-mail: fdallonder@gmail.com

$\star \star \star$ Doutorando e mestre em Economia pela Universidade Federal do Rio Grande do Sul.E-mail: pperfeitodasilva@gmail.com 
O presente artigo tem como objetivo geral discutir o papel do Estado na construção da infraestrutura e do setor industrial por meio de um estudo de caso determinado geográfica e temporalmente, a saber, os Estados Unidos ao longo do século XIX. Em tal país, a primeira metade do século em questão caracterizou-se por um conjunto de transformações na infraestrutura nacional, que culminou com a unificação do mercado interno e a emergência de inovações organizacionais. A partir disso, na segunda metade do século, a vitória nortista na Guerra de Secessão (1861-1865) ampliou a autoridade central estatal em diversas dimensões, o que impulsionou um modelo de desenvolvimento baseado no trabalho livre, no protecionismo industrial e no desenvolvimento do sistema bancário doméstico, viabilizando a ascensão do ciclo estadunidense de acumulação.

As políticas públicas de infraestrutura são amplamente difundidas com vistas à promoção do crescimento e do desenvolvimento econômico. Entende-se, no entanto, que seu impacto depende de uma série de outras variáveis, tais como sua relação com outras políticas, o tipo de relação entre Estado e sociedade, bem como a história da região.

No exame do caso dos Estados Unidos no século XIX, parte-se do argumento principal de que foi a expansão da intervenção econômica estatal que conferiu sentido à articulação entre infraestrutura e indústria no processo em tela. Isso significa dizer que os desdobramentos da infraestrutura sobre o setor industrial são contingentes, isto é, dependem de como o Estado e os diversos grupos sociais forjam uma trajetória específica de desenvolvimento. Por exemplo, a ampliação da malha ferroviária poderia tanto facilitar a exportação do algodão para o mercado britânico, advindo do latifúndio escravista sulista, quanto baratear a produção industrial nortista, devido à redução do custo dos alimentos oriundos das pequenas propriedades do Oeste.

Para aprofundar tal argumento e realizar o objetivo geral apresentado no primeiro parágrafo, este artigo organiza-se em três seções, além das considerações finais. Na primeira, detalha-se o conjunto de mudanças infraestruturais ocorridas ao longo do século XIX, atentando para a relação entre elas e o desenvolvimento econômico. A seguir, são apresentados os aspectos contingentes, que confluíram para que o avanço na infraestrutura forjasse uma trajetória de desenvolvimento industrial. Nesse sentido, na segunda seção, trata-se a Guerra de Secessão como 
marco situacional, a partir do qual se consolidou uma determinada visão de futuro, compartilhada pela autoridade estatal e por grupos sociais que a apoiavam, que fortaleceu a via industrializante para o desenvolvimento. Na terceira seção, observa-se como a autoridade estatal, com a capacidade de intervenção decorrente do resultado da Guerra de Secessão, expandiu-se e, a partir disso, impulsionou medidas como a aceleração da produção industrial, a consolidação do sistema bancário doméstico e a articulação com a infraestrutura. Tais transformações permitiram a unificação do mercado nacional e a edificação de uma estrutura produtiva baseada na competição entre grandes corporações verticalmente integradas (concorrência oligopolista).

Por fim, sublinha-se que o estudo de caso acerca do desenvolvimento da economia estadunidense é relevante basicamente por três motivos. São eles:

1) a exposição de instrumentos que podem ser utilizadas em processos nacionais diversos;

2) a desmistificação de políticas desenvolvimentistas que, após serem utilizadas pelos países centrais, são combatidas nos países periféricos $^{1}$

3) a compreensão de dilemas políticos e socioeconômicos que foram enfrentados pelo sistema nacional norte-americano e que, em certo aspecto, apresentam-se no horizonte da maioria dos países em desenvolvimento.

\section{Infraestrutura e desenvolvimento: uma síntese do caso estadunidense}

A “revolução dos transportes" nos EUA, nos termos de Taylor (1977), teve papel especial no contexto de transformação econômica a partir

\footnotetext{
Nesse ponto, faz-se referência ao estudo de Chang (1999). Na obra, o autor apresenta diversos exemplos históricos de políticas implementadas por países desenvolvidos, as quais receberam a oposição dos mesmos países, quando tentaram ser executadas por parte de países em desenvolvimento em períodos históricos posteriores. Tal ação dos países desenvolvidos na política internacional é batizada de "chutando a escada", e dá nome ao livro.
} 
da intervenção estatal na economia dos Estados Unidos. Mesmo antes da Guerra Civil de 1865, obras em rodovias, ferrovias, hidrovias e nas comunicações contribuíram com a unificação do mercado nacional, em um processo em que regiões aumentaram seu grau de especialização produtiva, e a manufatura artesanal perdeu espaço para a produção mecânica.

Naquele contexto, os custos de transporte eram muito elevados: "o custo de transporte de um bushe ${ }^{2}$ de trigo de Buffalo a Nova Iorque em 1817 era três vezes superior ao preço de mercado do produto; o de milho, seis vezes mais; o de aveia, 12 vezes" (Sellers; May; McMillen, 1990 , p. 122). Para reduzir o frete, foram executadas obras em diversos modais.

Nas rodovias, passou-se a adotar o modelo de estradas por pedágio. Em troca do pagamento de uma taxa, a companhia responsável pela estrada pavimentava e a conservava em bom estado, com funcionamento semelhante ao que até hoje vigora em diversos países. Esse sistema, lucrativo e eficiente, foi inaugurado em 1794 com a operação do primeiro pedágio em grande estrada. O sistema logo se espalhou do Nordeste para o Oeste dos EUA e se tornou uma febre. O auge desse processo foi a construção da Rodovia Nacional, em 1833, que se tornou a principal via de comércio Leste-Oeste (Sellers; May; McMillen, 1990, p. 122).

Nas hidrovias, foram utilizados canais e o barco a vapor. Até então, o transporte aquaviário era realizado por chatas, pequenas embarcações de pequeno calado e fundo chato, ou barcos a remo. Era, portanto, lento, custoso e cansativo. Entretanto, em 1807, Robert Fulton testou com sucesso o barco a vapor, o Clermont ${ }^{3}$. Após o fim da Guerra de 1812, a utilização dessa embarcação cresceu: em 1820, havia 60 dessas unidades; em 1860,já eram mais de mil. Seu custo era muito inferior ao dos barcos convencionais: $25 \%$ a $30 \%$ do valor das chatas e $5 \%$ a $10 \%$ do transporte de mercadorias efetuado pelos barcos de quilha (Sellers; May; McMillen, 1990, p. 122).

2 Bushel é uma unidade de capacidade para mercadorias sólidas utilizada nos países anglo-saxões. No caso do trigo, um bushel representa aproximadamente 27,2 quilogramas.

3 Em seu primeiro teste, o Clermont fracassou. Todavia, após alguns ajustes no motor, realizou com sucesso a viagem de 130 milhas, durante 32 horas, de Nova York até Albany pelo rio Hudson. 
Paralelamente, a construção de canais facilitava a conexão fluvial entre Leste e Oeste ${ }^{4}$. Em 1825, ficou pronto o canal de Erie, que permitiu a ligação do lago Erie com o rio Hudson, no estado de NovaYork. Ao permitir o tráfego na direção oeste, o canal favoreceu a ocupação e a expansão comercial intensa naquela direção. Outros canais também foram construídos, como o canal da Pensilvânia, ligando a região dos Grandes Lagos com os rios Ohio e Mississípi.

Em relação às ferrovias, em 1850 foram construídas diversas ligações, de modo que, ao final da década, o país contava com mais de 48 mil quilômetros; nessa década, foram construídas as principais ligações Leste-Oeste (Sellers; May; McMillen, 1990). Com traçados paralelos aos das ferrovias, as linhas telegráficas permitiam comunicações muito mais rápidas, influenciando operações comerciais e dinamizando o fluxo de informações. Ao final da década, os EUA contavam com 80 mil quilômetros de linhas telegráficas (Sellers; May; McMillen, 1990).A expansão das ferrovias constitui um marco do processo de desenvolvimento econômico, sublinhando a formação do capital financeiro estadunidense e seu potencial de acumulação a partir da capacidade de unificar mercados:

Foi sobre essa base que explodiu a ferrovia. Modificando radicalmente a escala de produção e de distribuição e o tamanho da firma, seus efeitos encadeados para trás e para frente foram de uma ordem até então desconhecida. Ela permitiu o encontro entre o vapor, o carvão mineral, o ferro, a construção civil (pela exigência de obras de infraestrutura, como pontes e terminais urbanos) e o Estado (como vetor da demanda); ela pressupõe um novo sistema de telecomunicações, que viria a surgir com o telégrafo; ela impulsiona o sistema fabril, não apenas pela demanda que exerce, mas oferecendo segurança e rapidez nos transportes e comunicação, e, acima de tudo, um modelo de organização empresarial que iria revolucionar o velho sistema produtivo. (Teixeira, 1999)

O tamanho do impacto dessas melhorias infraestruturais pode ser percebido a partir de alguns dados. Em 1815, uma carga transportada de Cincinnati a Nova York por barco de quilha e carroça levava mais de

4 Aqui é necessário levar em conta as dimensões do território dos EUA no início do século XIX. Nesse caso, o Oeste representa o oeste da região Nordeste, em direção ao interior do país, mas ainda sem atingir o Pacífico. 
50 dias; em 1850, 18 dias por batelões ${ }^{5}$ e apenas de 6 a 8 por ferrovias. Em relação às tarifas, em 1815 custavam de 30 a 70 centavos de dólar por tonelada-milha; em 1850, de 2 a 9 centavos por estrada de ferro e cerca de 1 centavo por batelão em canal (Sellers; May; McMillen, 1990). Portanto, fica clara a redução de custos de transporte que permitiu a integração do mercado norte-americano, inicialmente no sentido Leste-Oeste.

Essa unificação do mercado foi acompanhada por uma inovação no modelo de negócios. Por meio de parcerias entre setor privado e governo, realizavam-se as obras de infraestrutura: "a aliança mais notável entre as iniciativas pública e privada aos níveis estadual e municipal ocorreu na esfera de transportes, onde o progresso exigia obras além do alcance de indivíduos isolados ou mesmo de grupos" (Sellers; May; McMillen, 1990).

O apoio estatal ao setor privado ocorria de diversas formas. Primeiro, mediante suporte ao financiamento das obras, como o canal de Erie, construído com impostos estaduais de Nova York, e a primeira linha telegráfica, de Washington a Baltimore, financiada pelo Congresso. Segundo, o Estado estimulava a criação de companhias na área de infraestrutura, as quais se tornaram as pioneiras das modernas sociedades anônimas. Esse modelo foi utilizado pelas companhias ferroviárias e de pedágio, que levantavam capital a partir da subscrição de ações de estados e municípios por onde passavam. Tais companhias adotavam um formato de "responsabilidade limitada", isto é, o acionista era responsável na proporção das ações que o possuía. Terceiro, havia uma particularidade do regime de mercado: o Estado normalmente autorizava esse tipo de empresa a operar em regime de monopólio ou semimonopólio, de modo a gerar receitas extraordinárias para garantir a realização das obras nessa fase inicial de construção da infraestrutura.

Segundo Alfred Chandler Junior (1999), as primeiras empresas capitalistas modernas surgiram justamente no setor de ferrovias e telégrafos ${ }^{6}$. Tendo em vista a natureza de operações diversas em várias localidades,

5 Embarcações semelhantes a chatas, mas um pouco maiores e passíveis de serem utilizadas por motor a propulsão.

6 O telégrafo foi inventado em 1844 e, ao promover a ligação entre continentes por meio de cabos submarinos, produziu uma das maiores acelerações das comunicações na história da humanidade. 
bem como a necessidade de coordenar o transporte de mercadorias ou informações, essas empresas originaram as modernas técnicas de estatística e contabilidade, que posteriormente levam ao surgimento das grandes empresas de distribuição e produção.A coordenação administrativa prevalecia sobre os mecanismos de mercado, de modo que era possível obter economias de escala. Com base nessa experiência, Chandler Junior (1999) afirma que, na era da distribuição, as economias de escala eram originadas não pelo tamanho do mercado, mas, sim, pela velocidade com que uma empresa podia operar seu estoque de mercadorias (Chandler Junior, 1999). Essas inovações, tecnológicas e administrativas, permitiram a formação de conglomerados verticalmente integrados, que foram decisivos para a emergência de um ciclo sistêmico norte-americano e a vitória dos EUA na competição interempresarial e interestatal no século XX (Arrighi, 1996) ${ }^{7}$.

Segundo Couto (2012), o conhecimento sobre a experiência dos EUA esteve na origem de diversas ideias de List, que propôs um sistema ferroviário na Alemanha: "somente agora eu reconheço a relação recíproca que existe entre poder industrial e o sistema nacional de transportes, e que um nunca pode se desenvolver ao seu máximo sem o outro" (List, 1989, p. 2). Goethe, fascinado com as perspectivas dos EUA, afirmou:

Eu ficaria chocado se os Estados Unidos deixassem escapar de suas mãos essa magnífica oportunidade. É possível antever que essa jovem nação, com seu decidido amor pelo Oeste, terá ocupado, em trinta ou quarenta anos, a larga extensão de terra além das Montanhas Rochosas. (Goethe, 1962, apud Berman, 1986, p. 71)

Nesse processo de unificação do mercado, caracterizado pela redução de fretes e pela maior facilidade para a comunicação, empresas especializaram-se na produção. Como consequência, diversos produtores locais iam à falência, como resultado da competição. No setor de transportes,

7 Segundo Arrighi, "no meio século que se seguiu à Guerra Civil norte-americana, as empresas do país passaram por uma revolução organizacional que deu origem a um grande número de corporações verticalmente integradas e burocraticamente administradas. Elas começaram a se expandir no espaço transnacional assim que concluíram sua integração continental dentro dos Estados Unidos" (Arrighi, 1996, p. 290, grifo nosso). 
formou-se um novo tipo de empresa: a sociedade anônima.Todavia, para garantir o funcionamento de ambas, foram fundamentais os mecanismos protecionistas estatais. Por isso, na década de 1810, foi aprovada a primeira lei de proteção aduaneira, que visava preservar os produtores do Nordeste americano da concorrência estrangeira. Dessa maneira, importações de produtos como tecidos de lã e algodão, artigos de ferro e têxteis pagavam tarifas que variavam de $20 \%$ a $25 \%$ de seu valor, além de contar com outras medidas protecionistas posteriormente acrescentadas, como a Tarifa Morril, e o Internal Revenue Act ${ }^{8}$. A tarifa média aduaneira dos EUA para produtos manufaturados foi de $35 \%$ a $45 \%$ na década de 1820 (Chang, 2002). O país possuía, em seu estágio inicial de desenvolvimento, um dos maiores níveis tarifários do mundo (Amsden, 2009).

Portanto, a tríade indústria, infraestrutura e modelo empresarial, com corporações protegidas da concorrência estrangeira, marcou essa primeira fase do modelo de desenvolvimento norte-americano ${ }^{9}$. Após a Guerra de Secessão, essa tendência consolidou-se e expandiu-se, principalmente, por meio das ferrovias. Sobre a sua importância, o historiador Richard Stone afirma:

Eram muitas vezes o poder de vida e morte ao longo de um determinado local. Em áreas subdesenvolvidas, as ferrovias foram o fator determinante para determinar exatamente onde a ocupação iria ocorrer [...]. São frequentes histórias sobre cidades que não existem mais porque não foram capazes de atrair uma estrada de ferro, sem a qual seus produtos não conseguiam chegar ao mercado. (Stone, 1991, p. 2)

8 Lei instituída em 1862, que estabelecia as seguintes medidas: (1) criação da Comissão da Receita Interna, (2) cobrança de impostos especiais sobre o consumo de diversos bens e serviços, e (3) instituição do imposto de renda progressivo (Ashley, 1911).

9 Um dos principais autores intelectuais dessa visão foi John C. Calhoun, secretário de Estado e vice-presidente dos EUA. Nacionalista, Calhoun defendeu um conjunto de obras de infraestrutura com vistas à modernização econômica e à unificação nacional. Para tanto, defendia a importância de Marinha e Exército capazes, além de um banco nacional que financiasse a infraestrutura, um sistema de tributação e medidas protecionistas para defender a produção nacional, bem como para financiar as obras. 
Ora, as cidades fantasmas ilustram a destruição do tecido social que um mercado autorregulável pode gerar ${ }^{10}$. As necessidades de acumulação do capital, por si sós, podem transformar territórios e seus habitantes em mercadorias sujeitas às leis de oferta e demanda e à própria obsolescência. Em sua obra $A$ grande transformação, Karl Polanyi explica que a economia de mercado transformou o trabalho humano, a terra e o dinheiro em "mercadorias fictícias". Para o autor, os seres humanos e seus meios de vida foram alienados: convertidos em mercadorias, passaram a estar sujeitos à precificação (Polanyi, 2000). Por isso, os mecanismos de planejamento e intervenção estatal permitem gerir o mercado e orientar a transformação da produção e do território.

Em pouco mais de dez anos, os Estados Unidos praticamente quintuplicaram a extensão de sua rede ferroviária: em 1848, possuía 9.600 quilômetros de trilhos; em 1860, 48 mil quilômetros (Sellers; May; McMillen, 1990) ${ }^{11}$. Nesse período, foram concluídas as cinco grandes linhas-tronco que ligavam os portos de Boston, Nova York, Filadélfia, Baltimore e Charleston, do Atlântico aos vales dos rios Ohio e Mississípi (Sellers; May; McMillen, 1990) ${ }^{12}$. Tais linhas, conectadas a outras

10 Charles Tilly caracteriza as instituições políticas dos EUA nesse período da seguinte forma: "Ao olharmos atentamente para a política americana do século XIX, observamos, com certeza, muito racismo, nativismo, intolerância, violência, competição desenfreada e corrupção" (Tilly, 2007, p. 96).

11 Ao final do século, confirmando a tendência de expansão, os EUA possuíam um terço das ferrovias do mundo, totalizando cerca de 320 mil quilômetros de trilhos de aço (Sellers; May; McMillen, 1990).

12 O processo de expansão das ferrovias foi também acompanhado de forte descontentamento. As empresas tinham interesse na rentabilidade, de modo que desejavam que o trajeto da ferrovia fosse com o maior custo-benefício possível. Por outro lado, as comunidades desejavam ser incluídas nas rotas, ainda que o caminho não fosse o mais rentável. Pequenos e grandes produtores também barganhavam por tarifas vantajosas para escoar suas produções. Da mesma forma, havia conflitos entre os proprietários e os trabalhadores da construção das ferrovias, submetidos a péssimas condições laborais. Ainda, outro tipo de conflito ocorria entre operadores de ferrovias concorrentes: algumas rotas tinham mais de 20 linhas competidoras, como a que ligava St. Louis e Atlanta (1880). Por vezes, tentavam estabelecer cartéis que, contudo, fracassavam em razão de algum competidor quebrar o acordo para obter vantagem. Curiosamente, Fukuyama (2014) compara o papel das ferrovias no século XIX ao do sistema de saúde no século XXI: ambos representam quase um quinto do PIB americano, apresentam conflitos entre proprietários e usuários, alcance nacional; e necessitaram de regulamentação federal, e não estadual. A primeira agência reguladora federal foi criada com o propósito de supervisionar as ferrovias e evitar 
linhas integradoras menores, permitiam o transporte de passageiros e mercadorias por praticamente todo o território dos EUA:

As estradas de ferro mudaram a vida norte-americana ao ligar as matérias-primas aos centros de processamento, e a produção agrícola aos consumidores urbanos, padronizando tempo e hábitos de trabalho, interligando pontos distantes do mercado nacional e acelerando o desenvolvimento e o crescimento demográfico do Oeste. (Sellers; May; McMillen, 1990, p. 216)

Paralelamente à expansão das ferrovias, a produção de ferro e de aço, bem como a de manufaturados, foi multiplicada. Esse processo foi acompanhado pela crescente urbanização, associado a oportunidades de comércio geradas pelas novas redes infraestruturais. A indústria crescia com vigor e transformava a estrutura socioeconômica. Os habitantes da cidade demandavam bens de consumo; as indústrias, insumos de produção. Dados os elevados custos fixos de produção, somente grandes empresas conseguiam sobreviver. É nesse período que surgem os chamados "senhores da criação", os Rockfellers, com a Standard Oil e o primeiro truste construído em 1882; os Swifts, no processamento de carnes; Carnegie, que controlava $25 \%$ do aço produzido pelo país por meio de sua Companhia de Aço Carnegie; Morgan, que adquiriu as operações de Carnegie e fundou a U.S. Steel Corporation, responsável por $60 \%$ da produção siderúrgica norte-americana, além de construir um conglomerado com mais de 40 empresas atuantes em diversos setores; Vanderbilt, barão das balsas e das estradas de ferro (Sellers; May; McMillen, 1990 $)^{13}$ - enfim, grandes empresários detentores de enormes conglomerados, oligopólios setoriais (aço, comunicação, energia etc.).

Durante esse processo, que combina políticas de infraestrutura com expansão das indústrias, os EUA adquiriram o protagonismo global: em 1900,já eram a maior economia do mundo. Produziam a mesma quan-

práticas abusivas, a Interstate Commerce Commision (ICC), em 1887.Em 1917, após problemas de abastecimento durante a Primeira Guerra Mundial, o então presidente Woodrow Wilson nacionalizou o setor de ferrovias, que retornou ao setor privado poucos anos depois, em 1920.

13 Segundo Sellers, May e McMillen, “de 1888 a 1905, foram formados 328 conglomerados ou empresas consolidadas (representando 40\%, ou US $\$ 7$ bilhões, do capital industrial da nação), metade das quais exercia poder monopolista em suas indústrias" (Sellers; May; McMillen, 1990, p. 219). 
tidade de aço que Alemanha e Inglaterra juntas, e eram os maiores consumidores de petróleo. Entretanto, essa trajetória da tríade infraestrutura, indústria e modelo empresarial trouxe também prejuízos para a sociedade: "pequenas empresas faliram aos milhares, e foram incalculáveis os custos sociais dessa forte concentração de poder econômico" (Sellers; May; McMillen, 1990, p. 220). Em reação ao processo de concentração econômica, em 1890 foi decretado o Sherman Act, que buscava combater os trustes e estabelecer padrões mínimos de concorrência entre as empresas. Como resultado, a Standard Oil foi desmembrada em 1911 e, posteriormente, novas leis antimonopolistas foram adotadas no âmbito do New Deal (Castro, 2011).

De um modo geral, o processo de desenvolvimento estadunidense pode ser esquematizado da seguinte forma:

Figura 1 - Esquema de desenvolvimento estadunidense

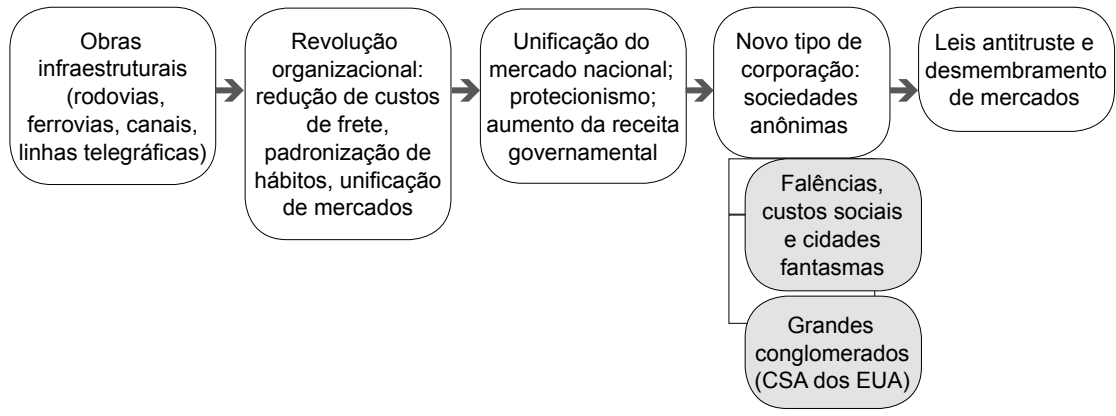

Fonte: elaboração própria.

Com efeito, o impacto da infraestrutura não pode ser considerado, per se, como gerador de externalidades exclusivamente positivas. Conforme se afirmou, a relação entre a infraestrutura e o desenvolvimento é contingente. Nesse caso, articulado com a indústria, tornou os EUA uma das maiores economias do globo, ainda que com geração de pobreza e prejuízos sociais. Todavia, essa precoce unificação de mercado ocorreu em um contexto único na primeira metade do século XIX, quando os fluxos de comércio global e as cadeias de produção eram incomparáveis com os da era da globalização contemporânea. Praticamente "isolados" do mundo e contando, ainda, com medidas protecionistas, o conjunto de medidas estatais, impulsionadas pela infraestrutura, 
contribuiu para gerar o ciclo sistêmico estadunidense durante o longo século XX e tornar o país uma superpotência. Sublinha-se que tal processo de ascensão foi marcado também por contradições, como se pode observar a partir do estudo da Guerra Civil estadunidense, cujo resultado, se diferente, poderia ter inviabilizado tal ciclo de expansão industrial.

\section{A Guerra de Secessão (1861-1865): o choque entre dois modelos de desenvolvimento}

A presente seção trata do marco situacional de um novo período da história político-econômica dos Estados Unidos. Assim, a Guerra Civil será apresentada como uma disputa entre duas alternativas de modelo de desenvolvimento e estratégia nacional.Além disso, será encarada como um tempo no qual a força política liberada pela vitória nortista (industrialista e intervencionista) permite que a autoridade estatal dê novos passos no sentido de promover um salto qualitativo no sistema econômico nacional e avançar na transformação e modernização das forças produtivas.

De acordo com Chang (1999), a ação estatal voltada à mudança estrutural deve atuar no sentido da formulação de uma visão de futuro para o conjunto da economia. Assim, ao perseguir uma estratégia de longo prazo, a autoridade estatal precisa arbitrar o conflito entre diferentes grupos sociais. Quando tais conflitos ocorrem em torno da própria visão de futuro, a solução do embate, por qualquer que seja o caminho, é condição para a perseguição de uma dada estratégia. Nesse sentido, a vitória nortista permitiu que a autoridade estatal, sob o comando do vitorioso Partido Republicano, formulasse uma visão de futuro em torno da industrialização estadunidense, dando esse sentido às mudanças infraestruturais precedentes e posteriores.

Quanto aos antecedentes históricos, Robertson (1967) observa que a colonização britânica, no território que viria a ser os Estados Unidos da América, se estabelece no século XVII. Dessa maneira,é consequência do avanço marítimo europeu e do comércio dirigido por tal continente, de modo que o pequeno potencial em termos de exploração de recursos naturais fez com que as colônias americanas fossem vistas como mercados consumidores dentro da lógica expansiva do capitalismo britânico. Como 
características importantes dessa colonização, tem-se o misto de motivação econômica (terra) e religiosa (liberdade para o culto puritano) dos colonos, a relação entre os fatores de produção (terra abundante, capital e trabalho escassos) e a divergência entre as regiões Norte e Sul acerca de modelos de desenvolvimento.

Acerca da disputa entre Norte e Sul, expõe-se a decisão de empregar escravos na região sulista diante do uso de servidão temporária na região nortista. A partir disso, foram construídas estruturas diversas de propriedade: a primeira, dominada pelo latifúndio escravista monocultor algodoeiro voltado à exportação e à relação de dependência com a Inglaterra (partindo de uma melhor condição em termos de recursos naturais); a segunda, dominada por pequenas propriedades fundiárias e pela evolução gradativa do setor manufatureiro e industrial (inicialmente, com o sistema doméstico e lidando com a questão da escassez e o alto custo do fator trabalho). Cabe ressaltar ainda que, nas colônias centrais, já se observava uma base de pequenas propriedades agrícolas produtoras de alimentos, o mesmo conteúdo que preencherá o Oeste americano, terceira região relevante no jogo político-econômico do país.

$\mathrm{Na}$ questão comercial, a região sulista mantinha fortes laços com a metrópole inglesa a partir da exportação de bens primários. Já a região nortista expandia sua classe comercial autônoma a partir da triangulação comercial de bens sulistas, alimentícios e manufaturados. Esse cenário era lastreado na autonomia cotidiana dos colonos e no leve controle econômico britânico. Não obstante, a crescente concorrência entre comerciantes ingleses e nortistas e o agravamento da situação econômica metropolitana a partir da Guerra dos Sete Anos com a França impeliram a Inglaterra a tomar medidas de restrição monetária nas colônias e de aumento da extração do excedente por meio de novos impostos materializados (leis do Selo e Townshend) ${ }^{14}$. Observa-se que ambas as medidas contrariavam interesses sulistas e nortistas, de modo que isso forjou uma unidade entre modelos diferentes de desenvolvimento, ainda que igualmente capitalistas e, em certa medida, opostos.

14 Conjunto de medidas institucionalizadas pelo Parlamento britânico (em 1765 e 1767, respectivamente), que buscava, seja pela cobrança de um imposto direto, seja pela racionalização da cobrança de taxas, aumentar a extração de recursos das colônias norte-americanas (Robertson, 1967). 
Em 1776, aconteceu a Revolução Americana, que, ao invés de apontar uma estratégia comum de desenvolvimento nacional, viabilizou a cristalização dos modelos econômicos diversos por meio da forte liberdade municipal e da noção de que as decisões devem ser tomadas tendo como centro os Estados, enquanto cabe à União tratar de interesses gerais amplos (como defesa nacional) e de exceções amplamente aceitas (Tocqueville, 1987). Isso fica mais claro em Moore Junior (1983), quando o autor relativiza a importância da Revolução Americana por entendê-la como uma disputa comercial entre a elite britânica e a elite estadunidense, tendo como principal saldo desse processo a unificação política, sem, todavia, não se constituir um mercado nacional e uma sociedade capitalista única.

Sobre a questão do protecionismo tarifário, Ashley (1911) aponta que, desde o processo de Independência, havia a tensão entre duas correntes acerca da industrialização: os que defendiam a construção de um sistema econômico autônomo por meio de proteção tarifária e de uma política econômica que promovesse incentivos à industrialização, e os que defendiam o livre-comércio a partir da inserção negociada no sistema econômico inglês por meio da especialização na produção de matérias-primas. É desse confronto que se origina a Guerra Civil entre o Norte, a favor da industrialização e do protecionismo, e o Sul agrícola, escravista e livre-cambista. Mais do que isso, as duas polarizações partidárias que caracterizam o século XIX (Whigs versus Jacksonianos e republicanos versus democratas) têm a questão tarifária como elemento central dos embates eleitorais.

List (1989) expõe o processo estadunidense de unificação e independência como resistência ao monopólio manufatureiro inglês. Pontua a ligação entre a proteção tarifária e o desenvolvimento de manufaturas locais, bem como a relação entre estas e a defesa nacional. Destaca-se a observação crítica que os estadunidenses fazem, em seu processo de afirmação nacional, da doutrina econômica majoritária à luz de necessidades práticas. Em um nível diferente de análise, Moore Junior (1983) nota que, em 1860, havia três modelos de desenvolvimento nos Estados Unidos: o Sul latifundiário escravista algodoeiro (ainda que capitalista), o Norte industrial e o Oeste dos agricultores independentes. A partir de 1830, a interdependência entre Norte e Oeste avançou - enquanto o Oeste se tornou responsável pelo abastecimento alimentar, o Norte 
notabilizou-se pelo provimento de bens industriais -, de modo que em 1860 havia duas sociedades igualmente capitalistas: o Norte industrial burguês e o Sul latifundiário escravista. Entretanto, tratava-se de modos de desenvolvimentos totalmente distintos. Assim,

Essencialmente, pergunta-se se as exigências institucionais para a operação de uma economia constituída por plantações à base da escravatura colidiam seriamente, em qualquer ponto, com as exigências correspondentes para a operação de um sistema industrial capitalista. [...] Deve também ser evidente que as necessidades, ou imperativos estruturais, para a escravatura das plantações e para o capitalismo industrial primitivo vão muito além dos sistemas econômicos em si e, sem dúvida, penetram na área das instituições políticas. As sociedades escravagistas não têm as mesmas formas políticas que as que se baseiam no trabalho livre. Mas, volta à nossa pergunta central, haverá algum motivo para que tenham de lutar. (Moore Junior, 1983, p. 117)

A crescente tensão entre a sociedade nortista, composta também pelo Oeste, e a sociedade sulista passa pela fundação e pelo fortalecimento do Partido Republicano em 1857, e se agrava com a vitória deste nas eleições presidenciais de 1860. Sobre tal partido político, Bensel (1995, 2000) refere-se a duas fases: a primeira, entre 1857 e 1877, na qual atuou como partido-Estado revolucionário e implementou uma série de transformações importantes para o processo de industrialização e desenvolvimento econômico nacional; e a segunda, entre 1877 e 1900, na qual cumpriu o papel de agente desenvolvimentista e articulador de uma ampla coalizão político-econômica em um sistema pluralista Estado-centrado. Compreende-se a ação do partido como revolucionária à medida que viabiliza a expansão da capacidade estatal e altera o escopo e conteúdo da economia nacional. Esse processo se esgota a partir do momento que o capital financeiro, criação do partido-Estado revolucionário e grupo social cliente, passa a atuar como obstáculo à expansão das capacidades estatais. Na seguinte passagem são expostos os princípios do partido:

A coalizão do Partido Republicano que promulgou essas políticas construiu o Estado americano sob dois princípios. O primeiro foi um nacionalismo robusto que fez da lealdade à União um pré-requisito para a 
representação nas instituições do Estado. Esse nacionalismo encontrou sua expressão mais pura na reconstrução militar do Sul após a Guerra Civil, mas também pode ser atribuído ao domínio das leis marciais nas regiões fronteiriças durante a própria guerra e às tentativas esporádicas de nacionalizar direitos de sufrágio após o período conhecido como Reconstrução. O segundo princípio propunha uma economia política na qual o poder do Estado central poderia eliminar as barreiras regionais e locais para o desenvolvimento de um mercado capitalista nacional e auxiliar diretamente na construção da infraestrutura fisica e financeira necessária para esse mercado. (Bensel, 1995, p. 10-11)

O projeto nacional republicano de expansão da economia capitalista e de avanço no sistema internacional se opunha à necessidade sulista de expansão territorial e abertura comercial. Observa-se que a economia latifundiária escravista é viável desde que não sofra pressões a partir da penetração de relações capitalistas, ou seja, a estratégia de integração econômica tinha uma barreira a superar.

Para Debouzy (1972), por sua vez, a constituição do Partido Republicano como partido dirigente do Estado a partir de 1860 é símbolo de um novo bloco histórico, cujos objetivos estratégicos são materializados no programa e nas decisões econômicas dos governos republicanos. Tal programa tinha como base os seguintes itens: ampliação da base de crédito, um sistema fiscal que proteja produtores industriais, um sistema bancário nacional, protecionismo, ferrovias, uma nova lei de terras para colonos e o desenvolvimento de maquinaria. Retomando Bensel (1995), o fortalecimento da alternativa capitalista autônoma propagada pelos republicanos se deu a partir da aliança Norte-Oeste. O conteúdo dessa aliança pode ser bem expresso a partir da sucessão de medidas como a Tarifa Morril ${ }^{15}$, a emancipação dos escravos, o Homestead Act ${ }^{16}$ e a ajuda federal para ferrovias.

Segundo Ashley (1911), o programa do Partido Republicano e sua aplicação, mediante a vitória nas eleições de 1860 e na Guerra Civil com

15 Lei tarifária protecionista instituída em 1861, após a redução de deputados livre-cambistas com o advento da Secessão (Ashley, 1911).

16 Foi instituída em 1862 e permitia que qualquer pessoa maior de 21 anos (inclusive mulheres e ex-escravos), que nunca houvesse entrado em guerra contra o governo federal e ocupasse uma parcela de terras por cinco anos, obtivesse a propriedade desta (Debouzy, 1972). 
os sulistas, nada mais é do que uma proposta de institucionalização e aprofundamento de um processo que vinha em evolução desde a guerra contra a Inglaterra, nas primeiras décadas do século. Assim, o protecionismo tarifário e o incentivo governamental à industrialização e modernização não são novidades de Lincoln, sendo esse tipo de política alvo de uma trajetória stop and go até 1860 , porém com clara tendência de evolução.A inovação que os republicanos trazem é o fim da mediação com os interesses sulistas (cujo símbolo é a abolição da escravatura) por uma série de ações que afirmam com radicalidade a opção pelo desenvolvimento econômico industrial e autônomo à Inglaterra. Dessa maneira, a Guerra Civil é o marco do controle dos interesses industriais sobre o governo e o momento de uma série de marcos do protecionismo tarifário, como a Tarifa Morril e o Internal Revenue Act. Cabe aqui expor que a ascensão republicana passou pela crise econômica de 1857, que enfraqueceu o argumento livre-cambista.

Por fim, em Teixeira (1999), o economista concorda com os autores anteriores e traduz a criação do Partido Republicano (1854) como marco que sela a unidade entre a burguesia industrial do Norte e os agricultores do Oeste. Dessa maneira, a vitória republicana em 1860 inaugura o ativismo estatal e a guerra entre dois modelos institucionais de desenvolvimento capitalista (agrário dependente versus industrial autônomo).

Para que possamos compreender a evolução do papel do Estado no desenvolvimento econômico estadunidense entre 1860 e 1900, é importante que se estabeleça um marco situacional - no caso, a Guerra Civil (1861-1865) - e, mais do que isso, é necessário enxergar nesse embate a resolução de contradições acumuladas no decorrer da história americana. A força política conquistada pela coalizão republicana com a vitória sobre a secessão sulista foi o combustível do qual se alimentou a ação estatal para empreender o salto qualitativo verificado na economia estadunidense entre 1860 e 1900.

Moore Junior (1983) apresenta as causas do confronto e a natureza da dificuldade de resolução por meios alternativos, sendo possível desconstruir visões mais simplificadas que se concentram em pontos importantes, mas não totalizantes como a abolição da escravidão, o protecionismo tarifário, entre outros. O sociólogo investiga as razões que inviabilizaram a conciliação entre os interesses dos grandes proprietários rurais (sulistas) 
e os interesses capitalistas industriais emergentes (nortistas em aliança com os agricultores independentes do Oeste). Como exemplo de acordo entre essas duas frações da classe capitalista, o autor expõe o caso alemão, mostrando que "era necessária a presença de circunstâncias históricas especiais para impedir o acordo entre uma sociedade agrária baseada em mão de obra escrava e um crescente capitalismo industrial" (Moore Junior, 1983, p. 118).

No debate econômico, havia três pontos que exigiam negociação entre Norte e Sul: a competição por capital por parte de duas sociedades em expansão, a necessidade crescente de mão de obra do Norte como pressão sobre a escravatura sulista e a questão da inserção estadunidense no comércio internacional, que se desdobrava tanto na oposição acerca do protecionismo tarifário, quanto na vinculação orgânica maior do Sul com a economia inglesa do que com a economia nortista. No caso alemão, questões muito semelhantes opunham os Junkers (aristocracia rural) e o nascente capital industrial. Não obstante, as pressões externas e o risco de revolta social por parte das classes dominadas sedimentaram o processo de conciliação. As características insulares estadunidenses tornavam o perigo externo não significativo na decisão das frações sociais, enquanto o risco social foi minorado a partir do aspecto incomum das relações entre capitalistas e trabalhadores nas primeiras fases do capitalismo estadunidense. Esse aspecto era a existência de terras livres no Oeste, que permitiu um processo de concessão de propriedade para as classes dominadas e a consolidação das forças do capitalismo competitivo e individualista.

Logo, a não existência de contingências observadas em outros casos nacionais e uma ampla problemática que, mesmo não sendo inconciliável em cada ponto específico, adquiriu uma totalidade de dificil negociação. Além disso, havia a incerteza quanto à evolução da correlação de forças e a disputa pelo conteúdo dos novos Estados (resultantes da Marcha para o Oeste). Construiu-se um cenário no qual "o aspecto fundamental tornou-se cada vez mais o fato de a maquinaria do governo federal ter de ser usada para apoiar uma sociedade ou a outra" (Moore Junior, 1983, p. 139).

$\mathrm{Na}$ mesma linha, Bensel (1995) traz uma análise centrada no Estado norte-americano que sobrevive e é transformado pelo processo de Guerra Civil, representada como uma guerra entre dois Estados (e sociedades) 
diversos: o Sul separatista versus o Norte sob a hegemonia do partido-Estado revolucionário que implementou uma série de transformações importantes para o processo de industrialização e desenvolvimento econômico nacional. O confronto entre Norte e Sul passa pela disputa entre um Estado com plenos atributos da soberania e a alternativa que propugnava uma mera coordenação no âmbito das relações internacionais, algo deveras complicado quando não alicerçado em uma base econômica nacional.

Segundo Debouzy (1972), a constituição do Partido Republicano como partido dirigente do Estado a partir de 1860 é símbolo de um novo bloco histórico, cujos objetivos estratégicos são materializados no programa e nas decisões econômicas dos governos republicanos.

A Guerra Civil engendrou a projeção estatal por meio de uma série de políticas. Bensel (1995) destaca que não havia sociedade unitária nos Estados Unidos e avança ao localizar a reação nortista à secessão sulista, como uma preocupação centrada na unidade nacional a partir de uma visão estratégica que antecipava o efeito cumulativo em outras regiões, como a fronteira oeste e áreas na própria base nortista. A origem do Estado passa, assim, pela repressão ao Sul e pela vantagem econômica nortista. Isso é visto na seguinte passagem, na qual são expostas as hipóteses do livro:

(1) A coalizão de classes republicana que conquistou o governo federal pouco antes da Guerra Civil produziu subsequentemente o confronto do Estado central com o separatismo do Sul. (2) O principal problema enfrentado pelos construtores de Estado não foi, portanto, associado a uma democracia robusta, mas ao separatismo do Sul. (3) Ao confrontar o separatismo, o Estado central passou da repressão violenta para uma solução centrada no Estado (envolvendo a Reconstrução) e, finalmente, para uma integração de mercado (fracamente efetuada). (4) Em suma, a formação do Estado norte-americano assumiu a forma de um programa industrial do Norte, no qual a integração política incompleta coincidia com a criação de mercados nacionais e a consolidação corporativa. (Bensel, 1995, p. 17)

Além disso, cabe registrar o que pensam os demais autores acerca desse evento histórico. Para Debouzy (1972), a Guerra Civil é um marco da transição entre classes sociais dirigentes do capitalismo estadunidense, como expõe em uma passagem da conclusão do livro: 
No período que estudamos, uma dupla modificação capital interveio: na conjuntura da guerra civil, os novos empresários e os especuladores conquistaram o poder detido antes da guerra pelos comerciantes, proprietários prediais e plantadores. A composição da classe dirigente modificou-se portanto. Por outro lado, esta classe não era senão a soma de grupos dirigentes locais, nas grandes cidades e regiões. Os seus interesses econômicos eram muitas vezes divergentes e até mesmo contraditórios. Após a guerra, a classe dirigente formou um grupo mais homogêneo. $\mathrm{O}$ movimento de concentração, a transformação da estrutura das empresas que daí resultou deu-lhe uma coesão mais forte e um poder financeiro considerável. O seu domínio sobre o governo federal ficou daí em diante solidamente estabelecido. (Debouzy, 1972, p. 301)

Segundo Arrighi (1996), a vitória nortista no confronto permitiu a formação de um território continental (que responde pelo territorialismo interno) e uma economia nacional forte, a partir da qual a economia dominante e autocentrada dos EUA diferencia-se da economia-líder extrovertida inglesa. Na mesma linha, Fiori (2007) sublinha a formação e unificação do mercado nacional, a redistribuição e centralização de poder. Assim, a reorganização do Estado nacional e do capitalismo se dá pela aliança weberiana entre Estado e capital financeiro, o que permitiu o avanço do imperialismo estadunidense. É a partir desse processo que se dá a nacionalização do Exército e do sistema bancário, a consolidação de uma dívida pública federal, um novo sistema de tributação e o financiamento da construção das ferrovias. É aí que se vê a autonomização do capital financeiro local e o incentivo à acumulação de capital a partir da queda do investimento inglês.

Para concluir esta seção, é preciso retomar Moore Junior (1983), reafirmando a noção de embate entre dois modelos de desenvolvimento antagônicos para os Estados Unidos. Modelos que propunham conteúdos éticos e programáticos diferentes para a intervenção estatal no processo de desenvolvimento econômico e industrialização. Trata-se de um confronto paradigmático que possui paralelo em diversos países ao redor do mundo. A vitória nortista significou o protecionismo tarifário à indústria, a abolição da escravidão, a constituição de um mercado nacional robusto e unificado, a integração produtiva nacional, um capitalismo autônomo e ascendente na estrutura econômica internacional. Nos termos de Chang (1999), abria-se caminho para consolidação de uma 
dada visão de futuro da economia, capaz de conferir sentido ao desenvolvimento infraestrutural e hierarquizar setores produtivos.

\section{Estado e desenvolvimento nos EUA}

No período compreendido entre os anos entre 1860 e 1900, o produto interno bruto (PIB) dos Estados Unidos ultrapassou a soma dos produtos da França e da Grã-Bretanha, países estes que em 1860 possuíam produtos individuais superiores ao dos Estados Unidos. No ano de 1900, a referida soma totalizava 301,608 milhões de dólares, ao passo que o PIB estadunidense apresentava 312,499 milhões de dólares (Maddison, 2013).

Tal trajetória de crescimento econômico decorreu de um conjunto de ações econômicas promovidas pela autoridade estatal, principalmente, em torno de três dimensões, as quais foram capazes de forjar uma articulação entre infraestrutura e desenvolvimento industrial. São elas: (1) bloqueio a medidas que poderiam fortalecer uma via oposta de desenvolvimento, ao favorecer o setor primário; (2) medidas estatais para proteção do setor industrial, formação da classe trabalhadora e viabilização da concentração de capital tanto no setor bancário, quanto no de infraestrutura; e, ao mesmo tempo, (3) manutenção da pressão competitiva sobre os capitalistas, ao regular a concentração em favor da concorrência oligopolista, impulsionando a competição por meio de inovações tecnológicas.

Sublinha-se que a relação entre a autoridade estatal e os agentes privados dos setores bancário e industrial também pode ser compreendida à luz do conceito de autonomia enraizada, que implica a combinação entre coerência interna do Estado, com sua capacidade de conexão externa, e a sociedade, a fim de promover a transformação industrial (Evans, 1993). Nos termos de Evans (2004), a autonomia enraizada decorre de duas dimensões: autonomia e parceria.A última refere-se ao grau de sinergia entre a burocracia e os grupos privados no processo de transformação industrial; enquanto a primeira, ao grau de independência da burocracia em relação ao capital privado nacional. O excesso daquela leva a um Estado predatório, avesso ao capital nacional, ou até mesmo 
a um desinteresse pelo setor privado. Já sua falta abre caminho à captura do Estado por grupos particulares e ao patrimonialismo.

Em relação ao papel de cada uma das dimensões, o autor afirma: “A parceria é necessária para obter informações e implementar políticas, mas sem a autonomia a parceria vai se degenerar em um supercartel" (Evans, 2004, p. 91). Nesse sentido, a combinação da segunda e da terceira dimensão do caso estadunidense reflete um alto nível de autonomia enraizada, aspecto presente em diversos exemplos de mudança estrutural.

No que tange ao enfraquecimento do setor primário, entre 1860 e 1900, observa-se a transferência de autoridade acerca da tomada de decisões econômicas dos governos estaduais para a autoridade federal (Bensel, 2000). Tal ação é relevante, uma vez que permite a construção de uma estratégia nacional de desenvolvimento aplicada coerentemente em todo o espaço econômico. Essas medidas inserem-se na lógica de constituição de um mercado nacional unificado, passo fundamental para o avanço da industrialização e da acumulação de capital a partir de ganhos de escala e da divisão espacial de tarefas, bem como da viabilização de certa autossuficiência da economia americana. Há ainda, como aponta Fiori (2007), medidas como a nacionalização das Forças Armadas e do sistema bancário, que transferem poder estadual ao governo central.

Passando-se às medidas estatais que forjaram o desenvolvimento industrial, sublinha-se a relação de parceria entre a autoridade estatal e o principal grupo social cliente entre 1860 e 1900: o capital financeiro. Para Robertson (1967), é possível observar que tal processo ocorre tanto pela institucionalização da dívida pública e pelo estabelecimento de um sistema bancário nacional a partir das Leis Nacionais Bancárias (1863 e 1864), quanto pela questão da oferta monetária que foi baseada em papel-moeda (Greenbacks) até 1879 e no padrão-ouro daí em diante.

Segundo Debouzy (1972), a ligação entre o governo republicano (eleito em 1860 e em Guerra Civil) e o sistema financeiro remonta ao financiamento do esforço de guerra por meio de emissões monetárias (greenbacks) e de empréstimos governamentais, o que permitiu o aumento do capital bancário pelo método favorável de resgate empregado pelo governo. A superação da desordem monetária existente entre 1836 e 1863, na qual cada Estado regulava seus respectivos bancos, deu-se pela 
instituição da primeira Lei Nacional Bancária (1863), que garantiu uma moeda forte e segura e um sistema com reservas adequadas, capital subscrito mínimo e títulos como base das emissões, algo também destacado em Robertson (1967). Essa reforma significou um reforço da hegemonia financeira do Nordeste estadunidense.

Além disso, a utilização das notas greenback (papel-moeda símbolo do abandono do padrão-ouro) e a emissão de títulos da dívida pública foram medidas fundamentais na diminuição da exposição externa, na viabilização do investimento, na manutenção de certo nível de meio circulante no sistema bancário nacional, na execução de políticas anticíclicas e no apoio à acumulação doméstica de capital (diminuição da dependência diante de investimentos externos europeus). Cabe ressaltar que as notas greenback foram funcionais ao movimento de bens e à reserva legal dos bancos. A concentração do sistema financeiro nacional no Atlântico Norte passou pelo apoio governamental e pelo projeto nacional de estabelecer uma região apta a disputar a condição de centro financeiro global com Londres.

Além da parceria com o capital financeiro, o programa do Partido Republicano também implicou ações nos seguintes eixos: protecionismo tarifário, ferrovias e transportes, reforma agrária e imigração. O marco do protecionismo é a Tarifa Morril de 1861, política que evoluiu entre 1864 e 1897 de um nível de tarifário médio de 47\% a 60\% (Robertson, 1967). O autor também observa que o avanço dos bens industriais e o declínio dos bens primários na composição das exportações permitiram a consolidação de saldos positivos na balança comercial a partir de 1876 . Bensel (2000), por sua vez, expõe os quatro setores beneficiados: os produtores de aço e ferro, as manufaturas de lã, os cultivadores de cana-de-açúcar e os criadores de ovelha.

Ashley (1911) apresenta dois momentos do protecionismo tarifário estadunidense. $\mathrm{O}$ primeiro destes se articula a partir do discurso que justifica as altas tarifas de importação como uma estratégia de proteção à indústria nascente e, portanto, de garantia do desenvolvimento nacional; a oposição a esse programa decorre do latifúndio escravista do Sul, que defende o livre-comércio e a inserção via venda de matérias-primas na divisão internacional do trabalho. A partir disso, a classe trabalhadora e os pequenos agricultores identificam-se com o discurso da burguesia 
industrial e são dirigidos por esta no campo político nacional-desenvolvimentista.

Por outro lado, a partir de 1890 (com o marco da Tarifa McKinley ${ }^{17}$ ), a indústria estadunidense não poderia mais ser classificada como infante. O protecionismo tarifário passa a ser baseado na justificativa de proteção ativa ao valor do trabalho. Observa-se que, nesse período, a burguesia industrial já havia incluído a elite agrária sulista em seu bloco histórico, enquanto os pequenos agricultores (Movimento Populista) e os trabalhadores (avanço sindical) passaram a, respectivamente, se opor ao protecionismo tarifário, por identificá-lo com os altos preços de uma economia sob o controle de oligopólios, trustes e monopólios, ou exigir deste uma maior parcela de seus ganhos.

Deve-se ressaltar ainda a questão ferroviária, que foi o principal fator de colonização, unificando o mercado e as comunicações nacionais, conforme exposto anteriormente. Cumpre registrar ainda que as ferrovias foram viabilizadas pela doação de terras públicas e por condições de crédito muito favoráveis, como indica Debouzy (1972). Também Teixeira (1999) compreende a expansão das ferrovias como marco do processo de desenvolvimento econômico, sublinhando a formação do capital financeiro estadunidense e seu potencial de acumulação a partir da capacidade de unificar mercados.

As ferrovias possuíram dois grandes papéis históricos: a integração do mercado nacional a partir da unificação política deste e a emergência do modelo da grande corporação moderna, conforme mencionado. A expansão das ferrovias passou pela sucessiva doação de terras públicas e se enquadrou em um processo mais amplo de expansão dos transportes e das comunicações (exemplo do telégrafo e do serviço postal). Como resultado, houve o avanço da industrialização e a transformação estrutural (sublinha-se a forte correlação entre malha ferroviária e desenvolvimento), o processo de integração e consolidação das grandes corporações (pools, trustes e holdings), o aumento da competitividade e da divisão espacial do trabalho, o avanço do desenvolvimento no Oeste e a formação de um modelo padronizado de consumo.

17 Lei aprovada em 1890, que elevou ao redor de 50\% a tarifa sobre importações nos Estados Unidos (Ashley, 1911). 
Quanto à reforma agrária, Debouzy (1972) atesta que, em 1862, o Homestead Act consolidou a aliança Oeste-Leste pela distribuição de terras livres e a constituição de um vasto mercado para as manufaturas. É importante notar que se tratou da primeira de uma série de leis agrárias e que, posteriormente, houve uma ação federal a favor do aumento da produtividade agrícola. Em relação à mão de obra barata, cabe mencionar a importância do Contract Labor Law ${ }^{18}$, que facilitou a entrada de imigrantes.

Segundo Kolko (1977), o avanço na regulação governamental da economia estadunidense é fruto da necessidade dos próprios capitalistas (e a pedido destes) a partir da falha dos mecanismos privados de estabilização e coerção do processo concorrencial,já que o processo de fusões (método privado) não conseguiu diminuir a competição intercapitalista (e manter o patamar da taxa de lucro) por fatores como o risco moral dos promotores privados de fusões. $\mathrm{O}$ autor expõe uma série de setores monopolizados e mostra a perda de poder relativo das firmas dominantes, assim como a falha do movimento de concentração em gerar estabilidade e controle econômico. Nessa conjuntura, a ação intervencionista do Estado é fruto da impossibilidade de racionalização voluntária dos capitalistas individuais.

Por fim, no que tange à manutenção da pressão competitiva, destaca-se a criação das Leis acerca do Comércio Interestadual $(1887)^{19}$ e do Sherman Antitruste (1890). Estas últimas consistem em ações do Estado central acerca do ambiente de mercado no sentido de restringir o poder de monopólio e as pressões monopolistas (Bensel, 2000). Robertson (1967) argumenta que o avanço do mercado interno, da integração nacional, da produtividade do trabalho, da administração científica (taylorismo) e da produção em massa gerou uma mudança no tamanho da firma em direção à concentração, conforme exposto na seção seguinte.

18 A Lei do Contrato de Trabalho, instituída em 1864, encorajava a imigração para os Estados Unidos, estabelecendo apoio para as empresas que arcassem com os custos de transportes dos trabalhadores imigrantes (Debouzy, 1972).

19 Primeira lei a instituir a regulação federal, por meio da primeira agência reguladora nacional (a Comissão Interestadual de Comércio), sobre o setor privado industrial. No caso, a medida impedia práticas monopolistas discriminatórias por partes de empresas privadas que geriam as ferrovias (Bensel, 2000). 
Consequentemente, o aumento do poder estatal, segundo essa dimensão, permitiu o redirecionamento do processo de integração produtiva, antes baseado em cartéis e trustes, para o modelo de corporações controladoras (holdings) assentado na integração vertical, como destacam Arrighi (1996) e Teixeira (1999). Tal aspecto dá suporte ao alto nível de autonomia enraizada da intervenção estatal estadunidense, afinal, a parceria na promoção de grupos alinhados ao desenvolvimento industrial e à autonomia do sistema financeiro doméstico não significou uma perda da autonomia da autoridade estatal, a qual logrou manter a pressão competitiva sobre os agentes privados, forçando-os à perseguição de ganhos de produtividade.

\section{Considerações finais}

O presente artigo buscou discutir o papel do Estado na construção da infraestrutura e do setor industrial no caso dos Estados Unidos, ao longo do século XIX. Em tal país, a primeira metade do século em questão caracterizou-se por um conjunto de transformações na infraestrutura nacional, culminando com a unificação do mercado interno e a emergência de inovações organizacionais. A partir disso, na segunda metade do século, a vitória nortista na Guerra de Secessão ampliou a autoridade central estatal em diversas dimensões, o que impulsionou o desenvolvimento industrial, viabilizando a ascensão do ciclo estadunidense de acumulação.

Praticamente "isolados" do mundo e contando, ainda, com medidas protecionistas, o conjunto de medidas estatais, impulsionadas pela infraestrutura, contribuiu para gerar o ciclo sistêmico estadunidense durante o longo século XX e tornar o país uma superpotência.

Reconhece-se que tal período de ascensão estadunidense ocorreu em um contexto único, na primeira metade do século XIX, quando não era preciso enfrentar a pressão da globalização. Por um lado, tal aspecto restringe a implementação de medidas semelhantes por parte de países emergentes e em desenvolvimento no contexto atual. Por outro, ainda que em contextos diferentes, a combinação entre planejamento da infraestrutura e política industrial logrou ser bem-sucedida em outros momentos históricos, como na experiência desenvolvimentista brasileira em meados 
do século XX ou mesmo na integração dos países da Europa Central à União Europeia na transição para o século XXI.

À guisa de conclusão, resgata-se o argumento de que o sentido do avanço na infraestrutura doméstica é contingente às medidas estatais quanto ao desenvolvimento industrial. Nesse sentido, uma melhora na infraestrutura sem o apoio do progresso industrial pode ampliar a dependência da economia nacional, facilitando a destruição de setores objetos de concorrência externa por parte de países mais competitivos.

Ao desenhar uma visão de futuro baseada no desenvolvimento industrial e, consequentemente, implementar um conjunto de medidas concatenadas a tal visão, a autoridade estatal estadunidense deu sentido ao avanço na infraestrutura, articulando-a a um processo mais amplo de mudança estrutural, o qual culminou com a emergência de um ciclo sistêmico de acumulação sob a liderança dos Estados Unidos.

Por fim, sublinha-se o elevado nível de autonomia enraizada dessa intervenção estatal, dado que a parceria na promoção de grupos sociais conectados ao desenvolvimento industrial e financeiro não significou uma redução da autonomia da autoridade estatal, a qual manteve a pressão competitiva sobre os agentes privados, de modo a impedir que o protecionismo temporário forjasse uma trajetória industrial de baixa competitividade externa.

\section{Referências bibliográficas}

AMSDEN, A. A ascensão do resto: os desafios ao Ocidente de economias com industrialização tardia. São Paulo: UNESP, 2009.

ARRIGHI, G. O longo século XX: dinheiro, poder e as origens do nosso tempo. São Paulo: UNESP, 1996.

ASHLEY, P. Modern tariff history: Germany-United States-France. 2. ed. New York: E. P. Dutton And Company, 1911.

BENSEL, R. F. Yankee leviathan: the origins of central State authority in America, 18591877. London: Cambridge University Press, 1995.

BENSEL, R. F. The political economy of American industrialization, 1877-1900. London: Cambridge University Press, 2000.

BERMAN, M. Tudo que é sólido desmancha no ar. São Paulo: Companhia das Letras, 1986. CASTRO,A. B. A reestruturação da indústria brasileira nos anos 90: uma interpretação. Revista de Economia Política. São Paulo, v. 21, n. 3, p. 3-26, jul.-set. 2011. 
CHANDLER JUNIOR, A. The visible hand: the managerial revolution in American business. Cambridge: Harvard University Press, 1999.

CHANG, H.The economic theory of the developmental State. In:WOO-CUMINGS, M. (org.). The developmental State. Ithaca/London: Cornell University Press, 1999.

CHANG, H. Kicking away the ladder: development strategy in historical perspective. London: Anthem Press, 2002.

COUTO, L. F. Desenvolvimento, integração e assimetrias: caminhos e descaminhos da aproximação regional na América do Sul. Brasília: Instituto de Ciência Política, Universidade de Brasília, 2012 (Tese de Doutorado em Relações Internacionais).

DEBOUZY, M. O capitalismo "selvagem” nos Estados Unidos (1860-1900). Lisboa: Estúdios Cor, 1972.

EVANS, P. O Estado como problema e solução. Lua Nova. São Paulo, n. 28-29, p. 107-157, 1993.

EVANS, P. Autonomia e parceria: Estados e transformação industrial. Rio de Janeiro: Editora UFRJ, 2004.

FIORI,J.L. O poder global dos Estados Unidos: formação, expansão e limites. In: FIORI, J. L. O poder americano. 3. ed. Petrópolis:Vozes, 2007, p. 11-64.

FUKUYAMA, F. Political order and political decay: from the Industrial Revolution to the globalization of democracy. New York: Farrar, Straus and Giroux, 2014.

GOETHE, J.W. Faust. Trad. Walter Kaufmann. New York: Anchor Books, 1962.

KOLKO, G. The triumph of conservatism: a reinterpretation of American history, 19001916. New York: The Free Press, 1977.

LIST, F. Sistema nacional de economia política. 3. ed. São Paulo: Nova Cultural, 1989.

MADDISON, A. Statistics on world population, GDP and per capita GDP, 1-2008 AD.

Disponível em <http://www.ggdc.net/maddison/oriindex.htm>. Acesso em 6/6/2013.

MOORE JUNIOR, B. As origens sociais da ditadura e da democracia: senhores e camponeses na construção do mundo moderno. São Paulo: Martins Fontes, 1983.

POLANYI, K. A grande transformação. 2. ed. Rio de Janeiro: Elsevier, 2000.

ROBERTSON, R. M. História da economia americana. São Paulo: Record, 1967, 2 v.

SELLERS, C.; MAY, H.; MCMILLEN, N. Uma reavaliação da história dos Estados Unidos. Rio de Janeiro: Zahar, 1990.

STONE, R. The Interstate Commerce Commission and the railroad industry: a history of regulatory policy. New York: Praeger, 1991.

TAYLOR, G. R. The transportation revolution, 1815-1860. Abingdon: Routledge, 1977. TEIXEIRA, A. Estados Unidos: a "curta marcha” para a hegemonia. In: FIORI, José Luís. Estados e moedas no desenvolvimento das nações. Petrópolis:Vozes, 1999, p. 155-190.

TILLY, C. Democracy. Cambridge: Cambridge University Press, 2007.

TOCQUEVILlE, A. A democracia na América. São Paulo: USP, 1987. 